\title{
Longitudinal study of respiratory health in dairy farmers: influence of artificial barn fodder drying
}

\author{
F. Mauny*, J.C. Polio*, E. Monnet**, D. Pernet*, J.J. Laplante+, \\ A. Depierre*, J.C. Dalphin*
}

Longitudinal study of respiratory health in dairy farmers: influence of artificial barn fodder drying. F. Mauny, J.C. Polio, E. Monnet, D. Pernet, J.J. Laplante, A. Depierre, J.C. Dalphin. (CERS Journals Ltd 1997.

ABSTRACT: Factors influencing respiratory consequences of dairy farming have not been extensively investigated to date. To evaluate the effects of barn fodder drying on respiratory symptoms and lung function, a 5 yr follow-up study was performed in the Doubs (France).

A cohort of male dairy farmers was analysed in 1990. The initial cross-sectional results suggested that barn-drying fodder may protect dairy farmers from lung function impairment. In 1995, 113 barn-drying farmers $(92 \%)$ and 231 traditionaldrying farmers $(84 \%)$ were re-analysed. Barn and traditional fodder-drying farmers were compared for prevalence of symptoms and spirometric measures of lung function.

After controlling for age, smoking status, altitude and cumulative exposure, barn-drying farmers compared to traditional-drying farmers had a lower prevalence of chronic bronchitis (4 versus $10 \% ; \mathrm{p}<0.05)$ and slightly higher values of forced expiratory volume in one second (FEV1) $(p=0.06)$ and FEV1/vital capacity (VC) $(\mathbf{p}<0.01)$. Nevertheless, decline of the respiratory function parameters was not significantly different between the two groups. Variables positively and significantly associated to longitudinal decline of lung function parameters were: age (FEV1, FEV1/VC); altitude (VC, FEV1) and chronic bronchitis and dyspnoea at the initial survey $(\mathrm{FEV} 1 / \mathrm{VC})$. Persistence and emergence of chronic bronchitis, dyspnoea and symptoms at exposure were also significantly associated to an acceleration in the annual decline of the respiratory function.

In conclusion, the mode of fodder drying does not seem to significantly influence the decline in lung function. Nevertheless, this study confirms the results of the initial cross-sectional analysis and supports the hypothesis that barn drying fodder may have a protective effect on respiratory health in dairy farming. Eur Respir J 1997; 10: 2522-2528.
Depts of *Chest Diseases and **Public Health, University of Besançon, and +Medical Dept of "Mutualité Sociale Agricole du Doubs", Besançon, France.

\author{
Correspondence: J.C. Dalphin \\ Dept of Chest Diseases \\ Hôpital Saint Jacques \\ 2 place Saint Jacques \\ 25000 Besançon \\ France
}

\section{Keywords: Barn fodder drying dairy farmers \\ longitudinal study \\ respiratory health}

Received: August 121996

Accepted after revision August 51997
Many epidemiological studies [1-3] have shown a close association between both acute and chronic respiratory diseases and agricultural occupational exposure. The risk of chronic impairment in lung function or chronic bronchitis has already been demonstrated or strongly suspected in grain workers $[4,5]$ and swine workers [6].

Dairy farmers have been less extensively studied. One study, in Finland, found that the annual incidence of chronic bronchitis appeared to be higher in farmers than in nonfarmer control subjects [7]. Controlled cross-sectional studies have suggested a moderate but significant impairment of expiratory flow rate in dairy farmers [810]. Occupational exposure, especially to organic dusts, has been incriminated $[3,4,11]$.

In the Doubs, a damp and rainy semimountainous region of France, dairy farming is the principal agricultural activity. Because of the label of quality on milk and cheese, there is no use of silo feeds, cereals, chemical fertilizers and pesticides. Thus, besides cow allergens which specifically play a role in asthma in dairy farmers [12], hay and micro-organisms inside consti- tute the principal occupational exposure. In this region, the haymaking season is rainy. For this reason, artificial barn fodder drying has become more widely used over the last 20 yrs. An aerobiological study conducted in the Doubs had shown that exposure to fungal and bacterial micro-organisms (thermophilic actinomycetes) was lower in modern farms than in traditional farms and in particular, that barn fodder drying very significantly reduced air contamination by thermophilic actinomycetes [13].

The present cohort study began with a cross-sectional study conducted in 1990 which suggested a protective effect of barn fodder drying on farmers' respiratory function [14]. In this cross-sectional study, two groups of male farmers, one using barn drying and the other traditional drying, were compared; barn-drying farmers had slightly but significantly better respiratory function flow parameters. Both groups were re-examined in 1995 in order to analyse factors influencing the evolution of symptoms and the decline of respiratory function, with special attention to use of barn fodder drying. 


\section{Methods}

The study was conducted in co-operation with the "Mutualité Sociale Agricole (MSA) du Doubs", the French national insurance health mutual for farmers, whose medical department organizes annual free check-ups for all their members. The protocol was approved by the "Comité Consultatif pour la Protection des Personnes dans la Recherche Biomédicale", the local review board for research involving human subjects. Informed written consent was obtained from each subject.

\section{Population}

A cohort was established in 1990, during MSA check-up sessions in five districts of the Doubs region in France. Two districts were located on plains at altitudes of 250 $400 \mathrm{~m}$; three were located on tablelands with altitudes of 700-1000 m. One thousand eight hundred and fifty seven farmers agreed to participate in the study and were examined in 1990 (response rate 81.2\%). Subjects included were male farmers, working exclusively on dairy farms and involved daily in cattle foddering. The barndrying group included all those farmers who had been using a barn drying system for at least 3 yrs $(n=123)$. The traditional storage group included the first five farmers examined at each session who had been using a traditional storage system $(n=274)$. Farmers using traditional storage resided in the same geographical area as the artificial drying farmers.

In 1994, each subject was contacted individually and invited to participate in an investigation identical to the one performed in 1990. An explanatory letter concerning the objectives of the study and its practical value was sent to each subject. Subjects refusing to participate were contacted by telephone in order to obtain information about the reasons for their refusal. Subjects agreeing to participate were convoked individually to a specific examination session. These subjects were asked to answer a medical and occupational questionnaire, and were given spirometrics tests. Both procedures were performed blind. All examinations were performed on a morning following a foddering shift, between January and May 1995.

\section{Questionnaires}

Questions on respiratory symptoms were adapted from the questionnaire of the American Thoracic Society [15]. The basis of the questionnaire and the wording of the symptoms were identical to those used in 1990. Chronic bronchitis was defined as cough and chronic expectoration for 3 months of the year or more for at least two consecutive years. Dyspnoea was defined as shortness of breath when hurrying on the level or walking up a slight hill. Semidelayed respiratory symptoms (SDRS) were defined as cough and dyspnoea with fever occurring 4-10 h after exposure to mouldy hay. Asthma was retained when previously diagnosed by a physician. Atopy was defined as a history of allergic symptoms (any nasal allergies including hay fever and/or eczema or any kind of skin allergy).
Nonsmokers (NS) were defined as those having smoked on average less than one cigarette, one cigar, or one pipe a day for a year. Current smokers (CS) smoked this amount or more, and exsmokers (ES) had stopped smoking at least 1 month before the time at which they filled out the questionnaire.

The main questions of the occupational questionnaire concerned the size of the farm, the size of the herd, the method of storing and drying fodder, and the type of tasks regularly performed (milking, foddering, etc.). Geographic distribution was dichotomized according to altitude (plain or tableland). Exposure to fodder was estimated by the number of bale-years, that is the number of average density bales of hay (or its equivalent when farmers used other sizes of bales or methods of hay storage) effectively fed by the subject to the cattle per day, multiplied by the number of years of foddering.

\section{Respiratory function tests}

The same portable pneumotachograph (Autospiro Minato AS 500; Medical Science Company Ltd, Osaka, Japan) as that used in 1990 was used to measure slow vital capacity (VC), forced expiratory volume in one second (FEV1), and forced mid expiratory flow (FEF 25-75). The spirometer was calibrated daily for atmospheric pressure, hygrometry and temperature, and periodically with a $1.5 \mathrm{~L}$ syringe. A minimum of three adequate measurements was required for each subject [16]. The best value was selected after correction to body temperature and ambient pressure, and saturated with water vapour (BTPS). For cross-sectional comparisons, values were expressed as a percentage of the European Community for Coal and Steel reference values, calculated in relation to sex, age and height [17].

\section{Data analysis}

Farmers no longer exposed to fodder in 1995 were excluded from analysis. Spirometric data considered as inadequate according to the recommendations used [16] were also excluded. The analysis was performed considering the initial assignment to one of the two fodder-drying groups, even if the subject had changed his type of fodder-drying between the two surveys.

Firstly, a cross-sectional analysis of the 1995 data was performed. Prevalence of symptoms was analysed using Cox's proportional hazards model to estimate prevalence rate ratios for fodder-drying, adjusted for age (in four classes: <40, 40-50, 50-60, >60 yrs), smoking habits (CS, ES, NS), exposure (bale-years in three classes: $<500,500-1000,>1000$ ) and location (plain $=0$, tableland $=1$ ) [18]. Multiple linear regression was used to estimate the effect of barn fodder drying on respiratory function parameters, adjusted for the covariates used in Cox's model. Age, smoking (pack-years) and exposure (bale-years) were used as continuous variables.

Secondly, a longitudinal analysis was performed. The annual decline of respiratory function parameters in the two groups (1995 value - 1990 value/number of years) was assessed by multiple linear regression, adjusting for age in 1990 (years), location (plain $=0$, tableland $=1$ ), 
smoking habits and exposure between the two surveys. Exposure was estimated by the number of bale-years over the $5 \mathrm{yr}$ period. Smoking habits were categorized as follows: nonsmokers; exsmokers before 1990; exsmokers between 1990 and 1995, current smokers having smoked less than 5 pack-years between 1990 and 1995; and current smokers having more than 5 pack-years between the two surveys.

Finally, the association between changes in respiratory symptoms during the study period and the annual decline of spirometric parameters was analysed for chronic bronchitis, dyspnoea, symptoms at exposure (cough or shortness of breath with wheeze) and semidelayed respiratory symptoms. The following three categories were considered: absence of symptoms in 1995 (whether or not symptoms were present in 1990), emergence of symptoms between 1990 and 1995; and presence of symptoms in 1990 and 1995. The course of respiratory symptoms was considered as an independent ordinal variable, assuming a continuous effect of the three classes of symptoms on annual decline in lung function. The effect of each symptom was analysed separately, adjusted for fodder drying type and covariates previously used by multiple linear regression.

Data analysis was performed using the BMDP statistical software package (BMDP Statistical Software ${ }^{\mathrm{TM}}$, BMDP, Los Angeles, USA). Standard statistical methods used included Chi-squared, Fisher's exact and Student's t-tests for univariate analysis. Cox's proportional hazards and multiple linear regression were used for adjusted multivariate analysis [19, 20]; interactions between significant covariates were tested. Adjustment in models was performed including potential confounders, not only those found during the analysis but also those known to be strong determinants of respiratory function. A p-value equal to or less than 0.05 was regarded as significant. Assumption for residual normality was assessed by normal probability plot of the residuals.

\section{Results}

\section{Characteristics of the study population}

A total of 372 subjects (94\%) from the original cohort were seen and re-examined at the second survey in 1995. The mean interval between the two examinations was $4.6 \mathrm{yrs}$. The reasons for nonresponse to follow-up were refusal (15 cases), death (five cases), lost to follow-up (three cases) and nonrespiratory severe illness (two cases). Twenty eight subjects were no longer exposed to fodder and were excluded from analysis; 24 subjects had effectively retired and four had changed jobs (two due to semidelayed respiratory symptoms). Fourteen farmers were excluded from spirometric parameter analysis. The reasons for exclusion were missing data in 1990 or in 1995 (nine cases), or measures considered as inadequate according to the adopted criteria (five cases). The distribution of farmers who had changed their type of fodder drying is as follows: 14 initially traditional-drying farmers $(5 \%)$ changed to barn fodder drying (two were symptomatic at exposure in 1990) and five initially barn-drying farmers (4\%) stopped barn fodder drying (one was symptomatic at exposure in 1990). Final analysis was performed on 330 subjects (83\%) for spirometric parameters and on 344 subjects (87\%) for the other variables (except for dyspnoea, for which seven subjects were not evaluable).

Comparison between the study group and farmers excluded or lost was performed for initial parameters. Subjects included in the study were younger and less frequently smokers. They lived at higher altitudes, more frequently used artificial drying methods, and had more cattle, but cumulative exposure to fodder was not different. The included group was less symptomatic (significant for chronic bronchitis, $\mathrm{p}<0.01$, and nearly significant for SDRS, $\mathrm{p}=0.06$ ). All respiratory function parameters (percentage of reference values) were significantly higher in the included group $(\mathrm{p}<0.01$ for $\mathrm{VC}, \mathrm{p}<0.001$ for FEV1 and $\mathrm{p}=0.05$ for FEV1/VC). Complementary analyses were realized with the group consisting of exfarmers and farmers lost to follow-up: smoking and type of fodder-drying were not significantly associated with either symptoms or with respiratory function.

\section{Cross-sectional analysis of the 1995 survey}

The two fodder drying groups were comparable for almost all demographic characteristics (table 1). Smoking status changes were not different between the artificial and the traditional drying group. Nevertheless, artificial-drying farmers lived more frequently in tablelands, had more cattle and were exposed more to fodder.

Table 2 shows the adjusted prevalence rate ratios (PRRs) of symptoms according to fodder drying in 1995. Only chronic bronchitis was significantly lower in the barn drying group (PRR: 0.32 ; $95 \%$ confidence interval (CI): 0.11-0.95). Tested interactions, including altitude-fodder-drying, were not significant.

Table 1. - Demographic characteristics in 1995 for barn-drying and traditional-drying farmers

\begin{tabular}{|c|c|c|c|}
\hline & $\begin{array}{l}\text { Barn } \\
\text { drying }\end{array}$ & $\begin{array}{l}\text { Traditional } \\
\text { drying }\end{array}$ & p-value \\
\hline Subjects $\mathrm{n}$ & 113 & 231 & \\
\hline Age yrs & $48.6 \pm 10.2$ & $47.9 \pm 12$ & 0.62 \\
\hline Height $\mathrm{cm}$ & $174.4 \pm 6.2$ & $173.9 \pm 5.6$ & 0.45 \\
\hline \multicolumn{4}{|l|}{ Smoking status } \\
\hline Current smokers & $26(23)$ & $39(17)$ & \multirow{3}{*}{0.38} \\
\hline Exsmokers & $25(22)$ & $53(23)$ & \\
\hline Nonsmokers & $62(55)$ & $139(60)$ & \\
\hline Pack-years* & $14.6 \pm 11.0$ & $15.3 \pm 12.2$ & 0.68 \\
\hline \multicolumn{4}{|c|}{ Alcohol consumption } \\
\hline$<10 \mathrm{~g} \cdot$ day $^{-1}$ & $40(35)$ & $97(42)$ & \multirow{3}{*}{0.36} \\
\hline $10-50 \mathrm{~g} \cdot \mathrm{day}^{-1}$ & $57(50)$ & $98(42)$ & \\
\hline$>50 \mathrm{~g} \cdot \mathrm{day}^{-1}$ & $16(14)$ & $36(16)$ & \\
\hline \multicolumn{4}{|l|}{ Geography } \\
\hline Plain & $9(8)$ & $47(20)$ & \\
\hline Tableland & $104(94)$ & $184(80)$ & $<0.01$ \\
\hline \multicolumn{4}{|l|}{ Exposure to fodder } \\
\hline Cattle ${ }^{\dagger}$ & $91.3 \pm 47.1$ & $70.3 \pm 35.0$ & $<0.0001$ \\
\hline Bale-years & $1180.0 \pm 604.4$ & $939.1 \pm 562.0$ & $<0.001$ \\
\hline
\end{tabular}

Values are given as mean \pm SD or as absolute number with percentage in parentheses. *: among current smokers and exsmokers; $\stackrel{\dagger}{*}$ average number during the $1990-1995$ period. 
Table 2. - Prevalence of symptoms and spirometric values in 1995 for barn-drying and traditional drying farmers

\begin{tabular}{|c|c|c|c|c|}
\hline & $\begin{array}{l}\text { Barn } \\
\text { drying }\end{array}$ & $\begin{array}{l}\text { Traditional } \\
\text { drying }\end{array}$ & $\mathrm{PRR}^{\dagger}$ & p-value \\
\hline \multicolumn{5}{|c|}{ Prevalence of symptoms } \\
\hline Subjects $n$ & 113 & 231 & & \\
\hline Atopy n & $11(10)$ & $25(11)$ & $0.96(0.46-2.01)$ & 0.92 \\
\hline \multicolumn{5}{|l|}{ Chronic symptoms } \\
\hline Chronic bronchitis & $4(4)$ & $22(10)$ & $0.32(0.11-0.95)$ & 0.04 \\
\hline Dyspnoea & $13(12)$ & $23(10)$ & $1.41(0.69-2.91)$ & 0.35 \\
\hline Asthma & $4(4)$ & $9(4)$ & $0.96(0.28-3.28)$ & 0.95 \\
\hline \multicolumn{5}{|l|}{ Symptoms at exposure } \\
\hline Eye irritation & $13(12)$ & $29(13)$ & $1.06(0.53-2.11)$ & 0.96 \\
\hline Nose irritation & $52(46)$ & $107(46)$ & $1.07(0.75-1.51)$ & 0.72 \\
\hline Cough & $18(16)$ & $64(28)$ & $0.64 \quad(0.3-1.10)$ & 0.11 \\
\hline $\begin{array}{l}\text { Shortness of breath } \\
\text { with wheeze }\end{array}$ & $10(9)$ & $37(16)$ & $0.61(0.09-1.93)$ & 0.18 \\
\hline SDRS & $2(2)$ & $11(5)$ & $0.40(0.09-2.38)$ & 0.26 \\
\hline \multicolumn{5}{|l|}{ Spirometric values } \\
\hline Subjects $n$ & 111 & 219 & & \\
\hline VC $\%$ pred* & $101.1 \pm 11.8$ & $101.2 \pm 13.0$ & & $0.87 \div$ \\
\hline FEV1 \% pred* & $99.8 \pm 13.2$ & $97.0 \pm 14.8$ & & 0.06 \\
\hline $\mathrm{FEV} 1 / \mathrm{VC} \%$ pred* & $98.9 \pm 8.1$ & $96.0 \pm 10.2$ & & $<0.01+$ \\
\hline FEF $25-75 \%$ pred* & $86.4 \pm 22.8$ & $82.0 \pm 23.8$ & & 0.08 \\
\hline
\end{tabular}

Values are absolute number with percentages in parentheses unless, otherwise stated. *: results are expressed as mean \pm SD percentage values (European Coal and Steel Community standards) calculated in relation to age, sex and height. ${ }^{\dagger}$ : prevalence rate ratio (confidence interval at 95 per cent) for barn drying versus traditional drying adjusted for age, smoking status, geography and cumulative exposure from Cox's model. Wald's statistic for fodder drying coefficient (traditional $=0$, barn $=1$ ) in multiple linear regression adjusted for age, smoking status, geography and cumulative exposure. SDRS: semidelayed respiratory symptoms (cough and dyspnoea with fever occurring $4-10 \mathrm{~h}$ after exposure to mouldy hay); VC: vital capacity; FEV1: forced expiratory volume in one second; FEF25-75: forced midexpiratory flow; \% pred: percentage of predicted value.

The percentage predicted values for FEV1, FEV1/VC and FEF25-75, but not for VC, were higher in barn drying farmers (table 2). The difference between the two groups was significant for $\mathrm{FEV} 1 / \mathrm{VC}$ and nearly significant for FEV1 and FEF25-75 after controlling for confounders. Further multiple regression analyses including alcohol consumption, smoking status expressed as CS, ES and NS, and number of cattle as an indicator of exposure were performed and did not modify the results.

\section{Longitudinal analysis}

After adjustment, the annual decline of FEV1/VC was nearly significantly lower in barn drying farmers. The annual declines of VC, FEV1 and FEF25-75 were not different between the two groups (table 3). Tested interactions were not significant. Further analyses using alcohol consumption, smoking status expressed as CS, ES and NS, and number of cattle as an indicator of exposure were performed and gave the same results. Table 4 shows regression models relating spirometric changes to individual determinants. Age and geography were positively and significantly correlated to the annual decline of respiratory function parameters. Smoking and cumulated exposure were not correlated with the changes in respiratory function.

The 1990 values of chronic bronchitis, dyspnoea, semidelayed respiratory symptoms and symptoms at exposure (cough or shortness of breath with wheeze) were separately tested. The 1990 values of chronic bronchitis and dyspnoea were positively and significantly cor- related to the annual decline of FEV1/VC ( $<<0.01$ and $\mathrm{p}<0.05$, respectively).

The course of symptoms for chronic bronchitis, dyspnoea, symptoms at exposure and semidelayed respiratory symptoms did not differ statistically between the two groups. After adjustment for confounders, there was a positive correlation between the annual decline of respiratory function and the course of symptoms categorized in three classes (absence in 1995, emergence between 1990 and 1995, and presence both in 1990 and 1995) (table 5). Interaction terms between the course of symptoms and drying type on decline in lung function were tested and were found not to be significant, suggesting a similar association between symptoms and changes in lung function in the two groups.

Table 3. - Annual decline of respiratory function for barn-drying and traditional-drying farmers

\begin{tabular}{|c|c|c|c|}
\hline & $\begin{array}{l}\text { Barn } \\
\text { drying }\end{array}$ & $\begin{array}{l}\text { Traditional } \\
\text { drying }\end{array}$ & p-value \\
\hline Subjects $\mathrm{n}$ & 111 & 219 & \\
\hline $\begin{array}{l}\text { Time between the } \\
\text { two surveys yrs }\end{array}$ & $4.5 \pm 0.3$ & $4.6 \pm 0.3$ & 0.27 \\
\hline $\mathrm{VC} \mathrm{mL} \cdot \mathrm{yr}^{-1} *$ & $-25.5 \pm 97.6$ & $-8.4 \pm 101.8$ & $0.27^{\dagger}$ \\
\hline FEV1 $\mathrm{mL} \cdot \mathrm{yr}^{-1 *}$ & $-36.3 \pm 67.7$ & $-35.5 \pm 80.0$ & $0.50^{\dagger}$ \\
\hline $\mathrm{FEV}_{1} / \mathrm{VC} \% \cdot \mathrm{yr}^{-1} *$ & $-0.46 \pm 2.1$ & $-0.68 \pm 1.8$ & $0.07^{\dagger}$ \\
\hline FEF25-75 mL:yr-1* & $-52.2 \pm 152.01$ & $-44.2 \pm 164.2$ & $0.85^{\dagger}$ \\
\hline
\end{tabular}

Values are mean \pm SD, or absolute number. *: annual decline of parameters. $\dagger$ : Wald's statistic for fodder drying coefficient (traditional $=0$, barn $=1$ ) in multiple linear regression, adjusted for age, smoking, geography and cumulative exposure. For definitions, see legend to table 2 . 
Table 4. - Annual decline in lung function (VC, FEV $1, \mathrm{FEV}_{1} / \mathrm{VC}$ ) according to exposure-related variables

\begin{tabular}{|c|c|c|c|c|c|c|}
\hline \multirow{2}{*}{$\begin{array}{l}\text { Independent } \\
\text { variable }\end{array}$} & \multicolumn{2}{|c|}{$\mathrm{VC}$} & \multicolumn{2}{|c|}{ FEV1 } & \multicolumn{2}{|c|}{$\mathrm{FEV}_{1} / \mathrm{VC}$} \\
\hline & Coeff. & SE & Coeff. & SE & Coeff. & SE \\
\hline Age yrs & -0.185 & 0.524 & $-1.003 *$ & 0.412 & $-0.028 * *$ & 0.010 \\
\hline Tableland & $-65.428 * *$ & 16.231 & $-58.678 * *$ & 12.917 & -0.408 & 0.325 \\
\hline Smoking & -9.532 & 9.124 & -0.006 & 0.014 & 0.053 & 0.182 \\
\hline Bale-years (1990-1995) & 6.394 & 6.942 & 2.089 & 5.491 & -0.043 & 0.138 \\
\hline Barn drying & -18.709 & 12.773 & 7.394 & 10.017 & $0.450 \S$ & 0.251 \\
\hline $\begin{array}{l}\text { Intercept } \\
\mathrm{r}^{2}\end{array}$ & \multicolumn{2}{|c|}{54.334} & \multicolumn{2}{|c|}{54.259} & 0.05 & \\
\hline
\end{tabular}

Regression coefficients (Coeff.) with positive values indicate a protective effect. All variables listed were included simultaneously in the multiple regression models. Each coefficient and p-value is controlled for all other variables. Age and bale-years are continuous variables; for tableland and barn drying, reference categories are plain and traditional drying, respectively. *: $\mathrm{p}<0.05 ; * *: \mathrm{p}<0.01 ; \S: \mathrm{p}<0.10$. For definitions, see legend to table 2 .

Table 5. - Annual decline in lung function (VC, FEV $1, \mathrm{FEV}_{1} / \mathrm{VC}$ ) according to change in symptoms status between 1990 and 1995

\begin{tabular}{|c|c|c|c|c|}
\hline & $\begin{array}{l}\text { Patients } \\
\text { n }(\%)\end{array}$ & $\mathrm{VC}$ & FEV1 & $\mathrm{FEV} 1 / \mathrm{VC}$ \\
\hline \multicolumn{5}{|l|}{ Chronic bronchitis } \\
\hline Not & $306(93)$ & & & \\
\hline New & $8(2)$ & & & \\
\hline Both & $16(5)$ & & & \\
\hline Regression coeff. & & $-48.369 * *$ & $-26.423 *$ & 0.069 \\
\hline Regression SE & & 16.703 & 13.285 & 0.335 \\
\hline $\mathrm{r}^{2}$ & & 0.11 & 0.09 & 0.05 \\
\hline \multicolumn{5}{|l|}{ Dyspnoea } \\
\hline Not & $291(90)$ & & & \\
\hline New & $19(6)$ & & & \\
\hline Both & $13(4)$ & & & \\
\hline Regression coeff. & & 8.149 & -17.995 & $-0.533^{*}$ \\
\hline Regression SE & & 12.623 & 10.008 & 0.249 \\
\hline $\mathrm{r}^{2}$ & & 0.08 & 0.09 & 0.05 \\
\hline \multicolumn{5}{|l|}{ Symptoms at exposure } \\
\hline Not & $238(72)$ & & & \\
\hline New & $59(18)$ & & & \\
\hline Both & $33(10)$ & & & \\
\hline Regression coeff. & & 17.114 & -11.882 & $-0.515^{*}$ \\
\hline Regression SE & & 11.442 & 9.148 & 0.228 \\
\hline $\mathrm{r}^{2}$ & & 0.09 & 0.08 & 0.05 \\
\hline \multicolumn{5}{|l|}{ SDRS } \\
\hline Not & $318(96)$ & & & \\
\hline New & $9(3)$ & & & \\
\hline Both & $3(1)$ & & & \\
\hline Regression coeff. & & 28.577 & 13.631 & -0.699 \\
\hline Regression SE & & 21.629 & 17.230 & 0.431 \\
\hline$r^{2}$ & & 0.09 & 0.08 & 0.05 \\
\hline
\end{tabular}

The effect of each symptom is analysed separately, adjusted for age, smoking, exposure, fodder drying type and geography by multiple linear regression. For each symptom, subjects were divided into three classes as follows: not symptomatic in 1995 or no longer symptomatic (not); became symptomatic between 1990 and 1995 (new); and symptomatic both in 1990 and in 1995 (both). The three classes are considered as an ordinal independent variable. $*: \mathrm{p}<0.05 ; * * \mathrm{p}<0.01$. For definitions, see legend to table 2 .

\section{Discussion}

This longitudinal study shows that the principal factors associated with an accelerated decline in respiratory function parameters are age (i.e. duration of exposure in this cohort), altitude and the existence of respiratory symptoms, especially when symptoms persist over the long-term. Furthermore, in 1995 as in 1990, barn-drying farmers had less chronic bronchitis and a slightly bet- ter respiratory function, but the artificial barn drying of fodder does not significantly reduce the annual decline in respiratory function.

Cross-sectional analysis on 1995 data shows artificial-drying farmers to be less symptomatic for chronic bronchitis and have better FEV1/ VC ratio values, both significantly. These results are consistent with and comparable to those found in 1990 [14]. In the initial analysis, however, the difference was slightly greater for respiratory function and the longitudinal study fails to prove that artificial barn drying of fodder could be used as a preventive method against long-term deterioration of lung function in dairy farmers. Nevertheless, the consistency of the results suggests that this technique contributes to maintaining good respiratory health in dairy farmers. It is possible that the preventive effect of barn drying was present before the beginning of the study in 1990, in a period when farmers worked in worse conditions on less mechanized farms. The aerobiological study we published in 1991, which demonstrated that barn drying fodder significantly reduced aerocontamination by micro-organisms, was carried out in 1987 [13]. These findings may no longer hold true. Moreover, a "healthy worker effect" at the constitution of the cohort cannot be excluded: the modernization of farming activities, including the installation of barn fodder-drying facilities, is costly and farmers with health problems (especially respiratory) might not be particularly tempted to undertake the work necessary to modernize their farm.

Potential selection biases should be also discussed. Nonanalysed farmers (deceased, lost to follow-up or excluded) were more symptomatic and presented lower respiratory function parameters than included subjects. This selection of healthier subjects has already been noted in other studies $[5$, 21]. Moreover, they were, for the most part, traditionaldrying farmers. This selective loss of less healthy, and more frequently traditional-drying farmers could have induced two consequences: a loss of power for the analysis and/or a reduction in the observed effect of barn fodder drying on symptoms and respiratory function. Within-subject variability is inevitable, but appears to 
be low [22]. Such variability could introduce a nondifferential measure bias, which could only reduce the power of our study, but not reverse the results found.

The annual decline of respiratory function parameters significantly increases with age. In this population of male dairy farmers, it is not possible to differentiate age effect from duration of exposure effect in that all the studied subjects were born on a farm. Baseline symptoms are predictive factors of a moderate accelerated decline of respiratory function; persistence and emergence of symptoms are associated with an accelerated decline of respiratory function. Some investigators have found the same results [23], others have not [24, 25].

Altitude appears to be one of the factors most influencing the acceleration in respiratory function decline. A previous study reported a nearly linear relation between the frequency of chronic bronchitis and farmer's lung disease, and altitude [26]. This could be explained by an increase in exposure to organic dust at higher altitudes; indeed, altitude and rainfall during haymaking are closely linked. The mean annual rainfall calculated for the last 20 yrs was about $1100 \mathrm{~mm}$ (285 during the haymaking season) in the two plains districts and 1700 $\mathrm{mm}$ (421 during the haymaking season) in the three tablelands districts (Regional Meteorological Centre, Besançon). Low temperatures, which are closely linked to altitude, could also be incriminated.

Hay and its micro-organisms constitute the main occupational exposure for Doubs dairy farmers, so cumulated exposure was evaluated by bale-years, which relate a quantitative, but not qualitative, aspect of exposure. No correlation appeared between bale-years and the annual decline of respiratory function. In a previous casecontrol study, we found no relation between bale-years and chronic bronchitis [27]. This may be explained by individual susceptibility; for equal exposure, some farmers develop a bronchial disease, while others do not. However, as there was no real measure of exposure, either quantitative or qualitative, this hypothesis must be put forward with caution.

No significant relation was observed between smoking habits and respiratory function evolution. This has already been observed in longitudinal studies [25, 28]. It may be due to the fact that our population contained few smokers $(22 \%)$, and those were moderate smokers. Also, farmers in this region rarely inhale smoke (observed data not evaluated in this study). It might also reflect a "healthy smoker effect" [29], i.e., the possibility that subjects who start and continue to smoke are particularly resistant to the effects of cigarette smoke. It may also be that the occupational exposure effect partly conceals the smoking effect as observed by PAHWA et al. [30] in grain workers exposed for more than $20 \mathrm{yrs}$ in industry. In our study as well, all the farmers were exposed for a long period of time because they were born on a farm.

This study does not prove the preventive effect of barn fodder drying against long-term deterioration of lung function in dairy farming. Nevertheless, this longitudinal analysis supports the results of the initial crosssectional study and suggests that this method of fodder storage may contribute to maintaining good respiratory health in male dairy farmers in the Doubs region of France. The negative influence of altitude justifies fur- ther studies in order to distinguish occupational exposure from climatical or other environmental effects.

Acknowledgements: The authors thank the dairy farmers who participated in this study and A. Gerbet, V. Abrial, A. Dubiez, V. Ninucci, M. Grenet, A. Tarallo, R. Fury and N. Peuteuil for their technical assistance.

\section{References}

1. Zedja JE, Dosman JA. Respiratory disorders in agriculture. Tubercle Lung Dis 1993; 74: 74-86.

2. Malmberg P. Health effect of organic dust exposure in dairy farmers. Am J Ind Med 1990; 17: 7-15.

3. Merchant JA. Agricultural exposures to organic dusts. Occup Med 1987; 2: 409-425.

4. Chan-yeung M, Enarson DA, Kennedy SM. The impact of grain dust on respiratory health. Am Rev Respir Dis 1992; 145: 476-487.

5. Chan-yeung M, Dimich-Ward H, Enarson DA, Kennedy SM. Five cross-sectional studies of grain elevator workers. Am J Epidemiol 1992; 136: 1269-1279.

6. Donham KJ. Health effect from work in swine confinement buildings. Am J Indust Med 1990; 17: 17-25.

7. Husman K, Koskenvuo M, Kaprio J, Terho Eo, Vohlohnen I. Role of environment in the development of chronic bronchitis. Eur J Respir Dis 1987; 71 (Suppl. 152): 5763.

8. Dalphin JC, Bildstein F, Pernet D, Dubiez A, Depierre A. Prevalence of chronic bronchitis and respiratory function in a group of dairy farmers in the French Doubs province. Chest 1989; 95: 1244-1247.

9. Heller RF, Hayward DM, Farebrother MTB. Lung function of farmers in England and Wales. Thorax 1986; 41: 117-121.

10. Babbott FL, Gump DW, Sylwester DL, MacPherson BV, Cynthia Holly R. Respiratory symptoms and lung function in a sample of Vermont dairymen and industrial workers. Am J Public Health 1980; 70: 241-245.

11. Rylander R. Lung diseases caused by organic dusts in farm environment. Am J Ind Med 1986; 10: 221-227.

12. Virtanen $\mathrm{T}$, Zeiler $\mathrm{T}$, Rautiainen $\mathrm{J}$, et al. Immune reactivity of cow-asthmatic dairy farmers to the major allergen of cow (BDA 20) and to other cow-derived proteins. The use of purified BDA 20 increases the performance of diagnostic tests in respiratory cow allergy. Clin Exp Allergy 1996; 26: 188-196.

13. Dalphin JC, Pernet D, Reboux G, Martinez J, Dubiez A, Barale T, Depierre A. Influence of mode of storage and drying of fodder on thermophilic actinomycete aerocontamination in dairy farms of the Doubs region of France. Thorax 1991; 46: 619-625.

14. Dalphin JC, Polio JC, Pernet D, et al. Influence of barn drying of fodder on respiratory symptoms and function in dairy farmers of the Doubs region of France. Thorax 1994; 49: 50-53.

15. Ferris BG. Epidemiology standardization project. Am Rev Respir Dis 1978; 46: 619-623.

16. American Thoracic Society. Standardization of Spirometry: 1987 update. Am Rev Respir Dis 1987; 136: 1285-1298.

17. Quanjer $\mathrm{PhH}$ (ed). Standardized lung function testing. Report working Party Standardization of Lung Function Tests, European Community for Coal and Steel. Bull Europ Physiopath Respir 1983; 19 (Suppl. 5): 195. 
18. Lee J. Odds ratio or relative risk for cross-sectional data? Int J Epidemiol 1994; 23: 201-203.

19. Hosmer DW, Lemeshow S. Applied logistic regression. Willey, New York, 1989; 25-81.

20. Kleimbaum DG, Kupper LL. Applied regression analysis and other multivariable methods. Duxbury press, Boston, 1978; pp. 131-243.

21. Van Pelt W, Borsboom JJM, Rijcken B, Scouten JP, Zomeren BC, Quanjer PH. Discrepancies between longitudinal and cross-sectional change in ventilatory function in 12 years of follow-up. Am J Respir Crit Care Med 1994; 149: 1218-1226.

22. Kunzli N, Ackermann-liebrich U, Keller R, Perruchoud AP, Schindler C. Variability of FVC and FEV1 due to technician, team, device and subject in an eight center study: three quality control studies in SAPALDIA. Eur Respir J 1995; 8: 371-376.

23. Sherman CB, Xu X, Speiger FE, Ferris BG, Weiss ST, Dockery DW. Longitudinal lung function decline in subjects with respiratory symptoms. Am Rev Respir Dis 1992; 146: 855-859.

24. Chan-yeung M, Schulzer M, Maclean L, et al. A follow-up study of the grain elevator workers in the port of Vancouver. Arch Environ Health 1981; 36: 7581.

25. Tabona M, Chan-yeung M, Enarson D, Maclean L, Dorken E, Schulzer M. Host factors affecting longitudinal decline in lung spirometry among grain elevator workers. Chest 1984; 85: 782-786.

26. Dalphin JC, Debieuvre D, Pernet D, et al. Prevalence and risk factors for chronic bronchitis and farmer's lung in French dairy farmers. Br J Ind Med 1993; 50: 941-944.

27. Dalphin JC, Pernet D, Dubiez A, Debieuvre D, Allemand $\mathrm{H}$, Depierre A. Etiologic factors of chronic bronchitis in dairy farmers. Chest 1993; 103: 417-421.

28. Frew AJ, Kennedy SM, Chan-Yeung M. Methacholine responsiveness, smoking and atopy as risk factors for accelerated FEV1 decline in male working populations. Am Rev Respir Dis 1992; 146: 873-883.

29. Becklake MR, Lallou U. The "healthy smoker", a phenomenon of health selection? Respiration 1990; 57: 137-144.

30. Pahwa P, Senthilsevan A, McDuffie HH, Dosman JA. Longitudinal estimates of pulmonary function decline in grain workers. Am J Respir Crit Care Med 1994; 150 : 656-662. 